\title{
Clinical and Surgical Findings and Outcome Following Rumenotomy in Adult Dairy Cattle Affected with Recurrent Rumen Tympany Associated with Non-Metallic Foreign Bodies
}

\author{
Z. Bani Ismail, A. Al-Majali and K. Al-Qudah \\ Department of Veterinary Clinical Sciences, Faculty of Veterinary Medicine, \\ Jordan University of Science and Technology, Irbid 22110, Jordan
}

\begin{abstract}
Medical records of 31 adult dairy cows suffering from recurrent rumen tympany for at least 1 month duration that underwent exploratory laparotomy and rumenotomy were reviewed and information was obtained on signalment, history, physical examination findings, laboratory findings and surgical findings. Cases were categorized according to surgical findings into 3 groups. Group 1 $(\mathrm{n}=10)$ included cattle with reticuloruminal, metallic foreign bodies and perireticular adhesions/inflammation, group $2(\mathrm{n}=14)$ included cattle with reticuloruminal, non-metallic foreign bodies and no perireticular adhesions/inflammation and group $3(n=7)$ included cattle with no reticuloruminal foreign bodies and no perireticular adhesions/inflammation. Anorexia and decreased milk production were the most common clinical signs in all groups. Reluctant to move and arched back were prominent in group 1 . In $45 \%$ of cases, frothy bloat was associated with the presence of large amounts of reticuloruminal, non-metallic foreign bodies. Collectively, factors that significantly had negative impact on outcome were: presence of perireticular adhesions, feeding finely-ground grain and plasma fibrinogen levels above $600 \mathrm{mg} \mathrm{dL}^{-1}$. However, the amount of grain fed per day and type of bloat (free-gas or frothy gas) had no significant effect on the outcome. Results of this study suggest that similar to metallic foreign bodies, non-metallic foreign bodies in the reticulorumen of adult dairy cattle are equally important in causing recurrent rumen tympany.
\end{abstract}

Key words: Gastrointestinal tract, surgery, rumen, bloat

\section{INTRODUCTION}

Recurrent rumen tympany is frequently a sign of digestive disease in young calves ${ }^{[1]}$. The tympany is usually moderate and results from accumulation of freegas in the reticulorumen ${ }^{[1,2]}$. In adult animals, free-gas bloat is less frequent and usually more acute because disturbances of the adult rumen tend to be more rapid and severe ${ }^{[1,2]}$. Rumen tympany is commonly associated with vagal indigestion in adult dairy cattle ${ }^{[1-5]}$. Damage to branches of the vagal nerve has been implicated as the main cause of this condition. However, experimental studies to simulate the disease by transecting these branches have yielded conflicting results $^{[2,3]}$.

Ingestion of metallic foreign bodies in adult dairy cattle can result in a wide variety of affections and syndromes that may impair reticuloruminal motility ${ }^{[4-6]}$. Traumatic Reticulo Peritonitis (TRP) is caused by penetration of a metallic foreign body through the reticular wall causing acute perireticular inflammation, adhesions and abscesses ${ }^{[5,6]}$. Perireticular adhesions may involve the vagus nerve resulting in impairment of reticular motility ${ }^{[5,6]}$. Non metallic foreign bodies are also commonly ingested by cattle causing a variety of ailments. In Jordan, plastic foreign bodies, ropes and pieces of old clothes are commonly found in the reticulorumen of small ruminants ${ }^{[7]}$. This observation has lead us to the belief that ingestion of such foreign bodies may comprise a large percentage of the causes of recurrent rumen tympany in adult dairy cattle. The objective of this study was to characterize the signalment, history, physical, laboratory and surgical findings and outcome in adult dairy cattle with recurrent rumen tympany following rumenotomy.

\section{MATERIALS AND METHODS}

Medical records of 31 adult dairy cattle presented to the Veterinary Health Center (VHC) at the Faculty of Veterinary Medicine of Jordan University of Science and Technology (JUST) because of recurrent rumen

Corresponding Author: Z. Bani Ismail, Department of Veterinary Clinical Sciences, Faculty of Veterinary Medicine, Jordan University of Science and Technology, Irbid 22110, Jordan 
tympany were reviewed. To be included in the study, the case should have had recurrent rumen tympany for at least one month duration and had exploratory laparotomy and rumenotomy performed.

For each case, history, age, parity, gestation status and calving dates were extracted from the medical records. Results of the clinical examination were also recorded and analyzed. Data collected included heart rate and rhythm, respiration rate, temperature, cardiac and pulmonary auscultation, rumen motility, orogastric intubation findings, withers pinch test and ferroscopy. In addition, findings of hematological and biochemical examinations including Packed Cell Volume (PCV), total White Blood Cell count (WBC), differential leukocyte count, Total serum Protein (TP) and plasma fibrinogen levels were analyzed.

Statistical analysis: The correlation between recurrent rumen tympany and different nutritional practices (type of ration, amount of grain offered and feeding finelyground grains) was analyzed using Chi-squire test. Similarly, the correlation between the outcome and various clinical and surgical findings was tested using Chi-square test. Paired independent student-t test was used to investigate the difference in the clinical and pathological findings in the 3 studied groups. All analyses were performed using SPSS software (SPSS Inc., Chicago, Illinois). Values of $\mathrm{P}<0.05$ were considered significant.

\section{RESULTS}

Clinicopathological findings: Thirty-one adult dairy cattle suffering from chronic rumen tympany underwent rumenotomy in the period between 2001 and 2005 were included in this study. The mean age was $3.8 \pm 1.4$ years and parity was $2 \pm 1$. All cattle were Holstein-Friesian cows. Of the 31 animals, $19(61 \%)$ were recently calved and $14(45 \%)$ were pregnant. The mean duration of illness was 3.7 \pm 4.6 months (0.5-24 months). In 23 (74\%) animals, tympany was recorded daily and in 8 (26\%) animals, at least 1 episode of tympany was recorded per week by the owner. In $16(52 \%)$ animals, episodes of tympany were closely associated with feeding times. In $18(58 \%)$ animals, a previous treatment was administered by the owner with no favorable response. Therapies administered included Poloxalene-containing products, magnesium sulfate orally, vegetable oils, various types of household detergents and paraffin oil. All animals were housed in tie-stall barns and were fed grain-based diet 3 times per day.
Table 1: Clinical findings in adult dairy cows with recurrent rumen tympany $(\%)$

\begin{tabular}{lccc}
\hline Clinical sign & $\begin{array}{c}\text { Group 1 } \\
(\mathrm{N}=10)\end{array}$ & $\begin{array}{l}\text { Group 2 } \\
(\mathrm{N}=14)\end{array}$ & $\begin{array}{l}\text { Group 3 } \\
(\mathrm{N}=7)\end{array}$ \\
\hline Partial anorexia & 30 & 86 & 57 \\
$\begin{array}{l}\text { Complete anorexia } \\
\begin{array}{l}\text { Decreased milk } \\
\text { production }\end{array}\end{array}$ & 70 & 14 & 14 \\
Arched back & 100 & 93 & 71 \\
Fever & 90 & 0 & 0 \\
Reluctant to move & 80 & 21 & 14 \\
Brisket edema & 90 & 14 & 0 \\
\hline
\end{tabular}

The diet consisted of barely, corn and soybeans mixture. The grain diet was processed to a finelyground mix in $17(55 \%)$ of the animals. Limited amount of hay was fed separately.

The major clinical signs recorded in various groups are shown in Table 1. In 11 (35\%) animals, tympany was mild with no apparent respiratory distress and in 20 $(65 \%)$, tympany was moderate to severe with varying degrees of respiratory distress. The rectal temperature varied from $38{ }^{\circ} \mathrm{C}$ to $39.5{ }^{\circ} \mathrm{C}$. The mean of rectal temperature was highest in group $1\left(39{ }^{\mathrm{O}} \mathrm{C} \pm 0.5\right)$ and lowest in group $2\left(38.8{ }^{\circ} \mathrm{C} \pm 0.5\right)$. The mean of heart rate in groups 1, 2 and 3 were $75.5 \pm 18,69 \pm 12$ and $72 \pm 6$ beats per minute, respectively. The mean of respiratory rate in groups 1,2 and 3 were $32 \pm 12,30 \pm 8$ and $30 \pm 4$ breaths per minute, respectively.

Rumen motility was reduced in all cows. By orogastric intubation, $11(35 \%)$ cows had free gas bloat and $20(65 \%)$ cows had frothy bloat. Withers pinch test was positive in $7(70 \%), 3(20 \%)$ and $1(14 \%)$ cows in groups 1, 2 and 3, respectively. The ferroscope was used in 25 cows. In $16(64 \%)$ cows, the ferroscope detected ferromagnetic foreign objects in the ventral abdominal area. By abdominal auscultation and percussion, 5 cows had a ping on the left paralumbar fossa indicating concurrent Left Displacement of the Abomasum (LDA).

In the hematological profile, a significant increase in total WBC count was reported in group 1 $\left(12.8 \pm 3.6 \times 10^{3}\right.$ cells $\left.\mu \mathrm{L}^{-1}\right)$ compared to group 2 $\left(7.8 \pm 1.3 \times 10^{3}\right.$ cells $\left.\mu \mathrm{L}^{-1}\right)$ and group $3\left(6.6 \pm 2.5 \times 10^{3}\right.$ cells $\mu \mathrm{L}^{-1}$ ) (Table 2, Fig. 1). In the differential leukocyte count, significant increase in the percentage of neutrophils were found in group $1(54.5 \% \pm 11)$ compared to group $2(43 \% \pm 2.6)$ and group 3 $(42.5 \% \pm 2.4)$ (Table 2, Fig. 1). There was a significant decrease in the percentage of lymphocytes in group $1(47 \% \pm 16)$ compared to groups $2(63 \% \pm 8.8)$ and group $3(60 \% \pm 8.7)$. There was no significant change in $\mathrm{PCV}$ values between the different groups. 
American J. Animal \& Vety. Sci., 2 (3): 66-71, 2007

Table 2: Hematological and some biochemical parameters in cattle with recurrent rumen tympany

\begin{tabular}{llccr}
\hline Groups & Parameter & Mean \pm SD & Range & Percentage of population \\
in the reference range
\end{tabular}

In the biochemical profile, serum total protein was significantly increased in group $1\left(7.9 \mathrm{~g} \mathrm{dL} \mathrm{dL}^{-1} \pm 1\right)$ compared to group $2\left(6.5 \mathrm{~g} \mathrm{dL}^{-1} \pm 0.6\right)$ and group $3(6.5 \mathrm{~g}$ $\mathrm{dL}^{-1} \pm 0.5$ ) (Table 2, Fig. 1). Plasma fibrinogen level was significantly increased in group $1(850 \mathrm{mg}$ $\left.\mathrm{dL}^{-1} \pm 280\right)$ compared to group $2\left(550 \mathrm{mg} \mathrm{dL}^{-1} \pm 120\right)$ and group 3 (470mg dL $\mathrm{m}^{-1} \pm 70$ ).

Surgical findings: All cows included in this study underwent standing left flank laparatomy and rumenotomy under local analgesia using $2 \%$ lignocaine hydrochloride. Pre-operative antibiotics were administered to all cows. In 5 cows with concurrent LDA, abomasopexy was performed to correct the position of the displaced abomasum.

In group 1, abdominal exploration revealed cranial abdominal adhesions of varying degrees between the reticulum and left body wall or between the reticulum and diaphragm in all cows. Pericarditis was diagnosed in 1 case and intra-abdominal abscessation was found in 2 cases. In this group, metallic foreign bodies consisting of nails and wires of different numbers and sizes were found in the ventral sac of the rumen and reticulum. In 7 cows, the metallic object was actually penetrating the reticular wall. No non-metallic foreign bodies were found in the reticulorumen in this group. There was a significant $(\mathrm{p}<0.05)$ correlation between the presence of foreign bodies in the rumen and the presence of perireticular adhesions. Also a strong correlation $(\mathrm{p}<0.05)$ was found between finely-ground grain and the presence of adhesions.
In group 2, abdominal exploration revealed no perireticular adhesions or abscesses. Rumenotomy however, revealed the presence of large amounts (4-14 $\mathrm{kg}$ ) of non-metallic foreign bodies consisting of plastic materials and ropes. In addition, in 6 cows, varying numbers and sizes of nails and wires were found in the reticulorumen. None of these nails and wires was penetrating. In 7 cows, a rumen magnet was found in the ventral sac of the rumen.

In group 3, there were no abdominal adhesions or abscesses present. Rumenotomy revealed no foreign bodies in the reticulorumen. In one cow, a $3 \mathrm{~cm} \times 2 \mathrm{~cm}$, cauliflower-like growth was found at the cardia. This growth was removed and histological examination revealed a fibroma.

Outcome: Follow-up was available for 22 cows. Seventeen (77\%) cows recovered completely and returned to normal production levels according to owner's expectations. Five cows ( 3 cows from group 1 and 2 cows from group 2), tympany recurred and were slaughtered within 2 months following surgery.

Statistical analysis revealed that cows with perireticular adhesions, cows fed finely-ground grains and those with plasma fibrinogen levels above $600 \mathrm{~g}$ $\mathrm{dL}^{-1}$ had significantly $(\mathrm{p}<0.05)$ poorer outcome. However, the type of bloat (free-gas Vs frothy gas), the amount of grain fed per day and reproductive status of the cow had no significant effect on outcome. 
American J. Animal \& Vety. Sci., 2 (3): 66-71, 2007
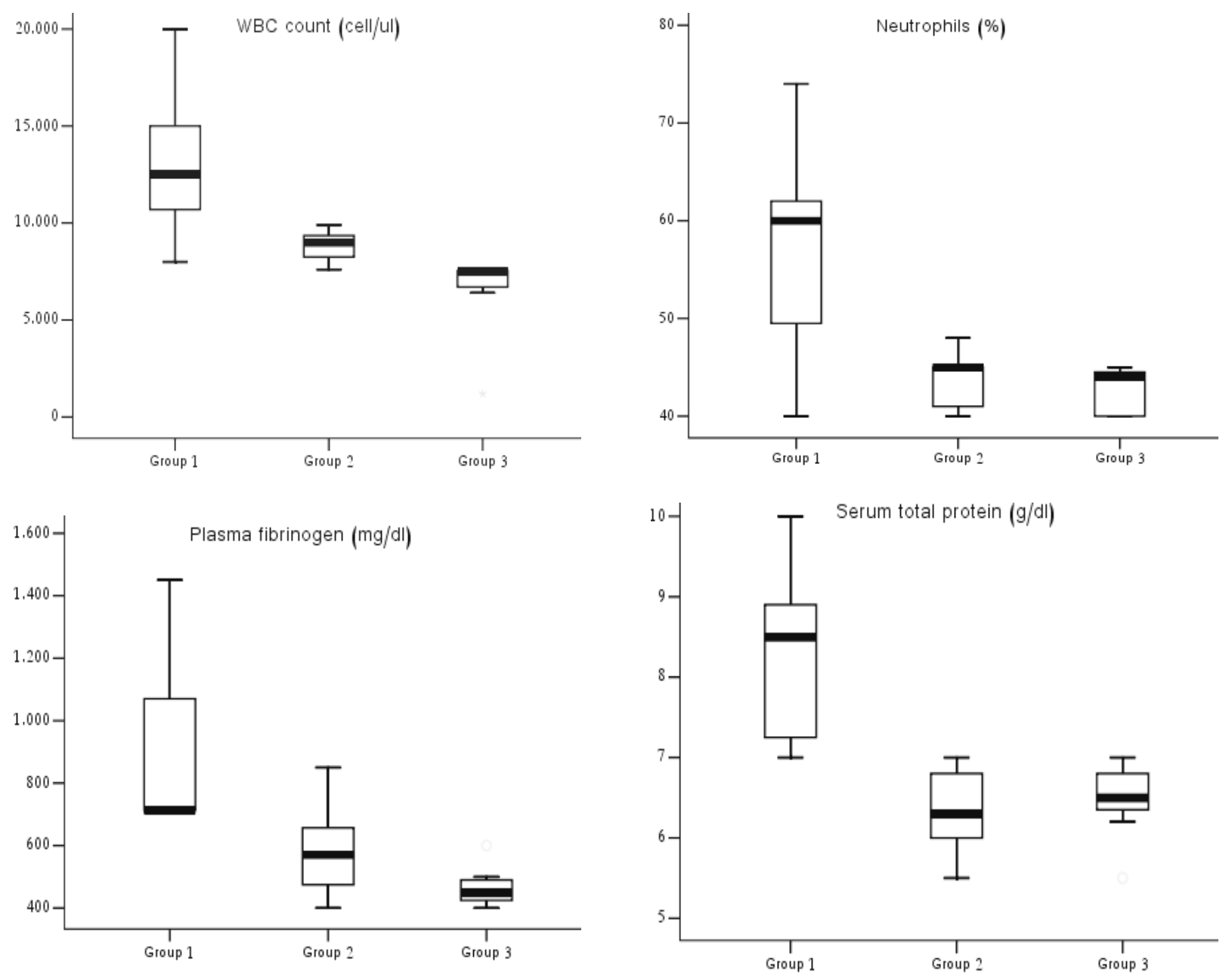

Fig. 1: White blood cell counts, neutrophil percentages, serum total protein and plasma fibrinogen levels in adult dairy cows affected with recurrent rumen tympany associated with metallic (group $1 ; n=10$ ) and non-metallic ruminal foreign bodies (group 2; $\mathrm{n}=14$ ) and in cows with no ruminal foreign bodies (group 3; $\mathrm{n}=7$ )

\section{DISCUSSION}

In this study, we reported the most common clinical and surgical findings in adult dairy cattle affected with recurrent rumen tympany. In addition, factors that may have had an impact on the outcome of such cows were also analyzed. Recurrent rumen tympany is a rare clinical disease in adult dairy cattle. The disease is more frequently diagnosed in young calves due to accumulation of free-gas in the reticulorumen due most likely to physical obstruction of the esophagus ${ }^{[1]}$. In this study, the majority of cows $(65 \%)$ were found to have frothy rumen contents. It has been reported that highly producing dairy cows fed large amounts of grain develop frothy or grain bloat ${ }^{[8]}$. In addition, grain bloat has been commonly diagnosed in confined animals in barns offered finely ground grains and an insufficient mount of roughages ${ }^{[8]}$. These diets contribute in changing the rumen microenvironment that favors froth production and reduce rumen motility leading to the condition. In Jordan, recurrent rumen tympany has been increasingly diagnosed in adult dairy cattle because of several management problems; firstly, most dairy cattle in Jordan are fed finely-ground, grain-based diets at the time of milking and secondly, roughage supply is inadequate and most of the cows are fed limited amounts of poor quality hay.

In this study, there was a strong correlation between the presence of perireticular adhesions or inflammation and feeding finely ground grains in the absence of penetrating foreign bodies. Moreover, cows 
fed these type of diets had poorer outcome. These findings are unique and interesting; feeding finely ground grains for a prolonged period of time may induce chronic ruminitis/reticulitis which may explain the perireticualr adhesions and inflammation leading to permanent impairment of reticuloruminal motitility. On the other hand, the amount of grain fed per day had no significant effect on outcome which can be difficult to explain. Cows can adapt to feeding large amounts of grain if this diet had been introduced gradually allowing the necessary alterations in the reticuloruminal microenvironment to take place.

Although, there are no reports in the current literature that links the presence of non-metallic foreign bodies in the reticulorumen with recurrent rumen tympany in adult dairy cattle, trichobezoars have been found associated with acute rumen tympany in calves and young cattle ${ }^{[9-11]}$. Because of the light weight of these objects, it was assumed that the trichobezoar is intermittently regurgitated into the cardia causing transient esophageal obstruction. In this study, however, no trichobezoars were found and the foreign materials were mostly plastic, ropes and pieces of old clothes. These materials were heavy (4-14 kg) and in some cases concreted and settled in the ventral aspect of the rumen and reticulum.

There was a strong correlation between the presence of non-metallic foreign bodies and the occurrence of recurrent bloat in cows involved in this study. The presence of large amounts of these materials in the reticulorumen may lead to over stretching and distension of these structures leading eventually to its fatigue. In addition, it has been reported that such objects may alter the histological structure of the reticuloruminal wall ${ }^{[7]}$. These pathological changes may further have a negative effect on reticuloruminal motility patterns and digestion processes leading to the condition. Furthermore, the presence of large amounts of foreign bodies in the reticulorumen may lead to alterations in the microbial populations of these digestive cavities contributing even more in the pathogenesis of the condition. This theory however, remains to be verified in the future.

In this study, we reported the most common clinical findings in adult dairy cows suffering from recurrent rumen tympany (Table 1). Similar to previous reports, the typical clinical signs of cattle with recurrent rumen tympany were anorexia, decreased milk production, arched back, fever and reluctance to move ${ }^{[12-15]}$. Most of these signs are related to abdominal pain and peritoneal inflammation.

In the hematological and biochemical profiles, neutrophilic leukocytosis and lymphopenia were evident in cattle with recurrent rumen tympany and TRP (Table 2). These changes are typical of acute inflammatory conditions in cattle. In addition, there was a significant increase in total serum protein concentration and plasma fibrinogen levels in these cows. These findings are in agreement with previous reports ${ }^{[16-19]}$.

\section{ACKNOWLEDGEMENTS}

We would like to thank clinicians and staff at the VHC at Jordan University of Science and Technology who participated in providing the data used in this study.

\section{REFERENCES}

1. Garry, F.B., 1996. Indigestion in Ruminants. In: Large Animal Internal Medicine (Ed., B.P. Smith) Mosby-Year Book, St. Louis, Missouri, pp: 824-858.

2. Whitlock, R.H., 1980. Bovine Stomach Diseases. In: Veterinary Gastroenterology (Ed., N.V. Anderson) Lea and Fibeger, Philadelphia, Pennsylvania, pp: 396-432.

3. Kuiper, R. and H.J. Breukink, 1986. ReticuloOmasal Stenosis in the Cow: Differential Diagnosis with Respect to Pyloric Stenosis. Vet. Rec., 119: 169-171.

4. Pinsent, J., 1988. Differential Diagnosis of Chronic Rumen Tympany in Cattle. In Practice, 3: 101-103.

5. Rehage, J., M. Kaske, N. Stockhofe-Zurwieden and E. Yalcin, 1995. Evaluation of the Pathogenesis of Vagus Indigestion in Cows with Traumatic Reticuloperitonitis. J. Am. Vet. Med. Assoc., 15: 1605-1611.

6. Fubini, S.L., N.G. Ducharme, H.N. Erb and W.C. Rebhun, 1989. Faluire of Omasal Transport Attributable to Perireticular Abscess Formation in Cattle: 29 cases (1980-1986). J. Am. Vet. Med. Assoc., 149: 811-814.

7. Hailat, N., S. Nouh, A. Al-Daraji, S. Lafi, F. AlAni and A. Al-Majali, 1996. Prevelence and Pathology of Foreign Bodies (plastics) in Awassi Sheep in Jordan. Small Rum. Res., 24: 43-48.

8. Blood, D.C. and O.M. Radostits, 1994. Veterinary Medicine, A Text Book of the Diseases of Cattle, Sheep, Pigs, Goats and Horses, 8th Ed. Bailliere Tindall, pp: 265-272.

9. Schweizer, G., M. Fluckiger, L. Metzger and U. Braun, 2005. Ruminal Tympany due to a Trichobezoar in a Heifer. Vet. Rad. Ultr., 46: 500-501. 
10. Patell, J.H. and D.M. Brace, 1995. Esophageal Obstruction due to a Trichobezoar in a Cow. Can. Vet .J., 36: 774-775.

11. Herd, R.M. and L.G. Cook, 1989. Hairballs in Feedlot-Raised Calves. Aust. Vet. J., 66: 372-373.

12. Sattler, N., G. Fecteau, P. Hélie, J.M. Lapointe, L. Chouinard, M. Babkine, A. Desrochers, Y. Couture and P. Dubreuil, 2000. Etiology, Forms and Prognosis of Gastrointestinal Dysfunction Resembling Vagal Indigestion Occurring after Surgical Correction of Right Abomasal Displacement. Can. Vet. J., 41: 777-785.

13. Herzog, K., M. Kaske, C. Bischoff, W. Kehler, M. Hoeltershinken, A. Starke, M. Stober and J. Rehage, 2004. Post Surgical Development of Inflammatory Adhesions and Reticular Function in Cows Suffering from Traumatic Reticuloperitonitis. Dtsch. Tierarztl. Wochenschr., 111: 57-62.

14. Misra, S.S. and S.J. Angelo, 1974. An Experimental Study on Traumatic Reticuloperitonitis in Bovines with Particular Reference to Diagnosis. Indian Vet. J., 51: 282-290.
15. Ramakrishana, O., J.M. Nigam and D. Krishnamoorthy, 1979. Biochemical Observations on Cows with Traumatic Pericarditis. Indian Vet. J., 56: 1044-1047.

16. Latimer, K.S., E.A. Mahaffey and K.W. Prasse, 2003. Duncan and Prasse's Veterinary Laboratory Medicine: Clinical Pathology, 4th Ed. Iowa State Press, Ames, pp: 338-342.

17. Dubensky, R.A. and M.E. White, 1983. The Sensitivity, Specificity and Predictive Value of Total Plasma Protein in the Diagnosis of Traumatic Reticuloperitonitis. Can. J. Comp. Med., 47: 241-244.

18. Jafarzadeh, S.R., I. Nowrouzian, Z. Khaki, S.M. Ghamsari and F. Adibhashemi, 2004. The Sensitivities and Specificities of Total Plasma Protein and Plasma Fibrinogen for the Diagnosis of Traumatic Reticuloperitonitis in Cattle. Prev. Vet. Med., 65: 1-7.

19. Gokce, H.I., G. Gokce and M. Cihan, 2007. Alterations in Coagulation Profiles and Biochemical and Haematological Parameters in Cattle with Traumatic Reticuloperitonitis. Vet. Res. Commun., 31: 529-537. 